\title{
Finite Element Analysis of Laser Cut Edge Beam Section for High Stress Intensity Structural Assessment
}

\author{
Daniel J. Thomas
}

Submitted: 19 May 2016/Published online: 7 June 2016

(C) ASM International 2016

\begin{abstract}
This research has analyzed the stability of laser cut-edges in the location of high stress intensity of a structural beam. The cut-edge characteristic properties formed during laser-cutting processing have been over prolonged periods determined to have beneficial effects on fatigue life. During this study two high strength steel grades S355MC and DP600 have been examined. Optimal fatigue lives were attained by minimizing the laser cutedge surface damage, maintaining the formation of shallow striations and by controlling the near edge microstructural deformations during the cutting process. This was validated using a bespoke component in which was tested under four-point loading in which there is a area of stress concentration forming a localized plastic zone. The importance of this region is critical due to the fact that it is the area that influences the fatigue life of the structure. Predicting the lives to crack initiation was determined through FE analysis which is based on the use of E-N cut-edge fatigue data.
\end{abstract}

Keywords Finite element analysis - Beam structures · Laser cutting $\cdot$ Fatigue failure $\cdot$ Structural durability

\section{List of Symbols}

$\begin{array}{ll}\text { A } & \text { Elongation to Failure } \\ \text { AHSS } & \text { Advanced High Strength Steel } \\ b & \text { Fatigue strength exponent } \\ c & \text { Fatigue ductility exponent } \\ \text { HAZ } & \text { Heat-affected zone } \\ \text { HCF } & \text { High cycle fatigue } \\ \text { HSLA } & \text { High strength low alloy }\end{array}$

D. J. Thomas $(\varangle)$

School of Engineering, Cardiff University, Cardiff, UK

e-mail: daniel.thomas@creationengineering.co.uk
$\begin{array}{ll}H_{\mathrm{V}} & \text { Vickers hardness } \\ K^{\prime} & \text { Cyclic hardening coefficient } \\ \mathrm{kPa} & \text { Kilopascal } \\ n^{\prime} & \text { Cyclic hardening exponent } \\ R_{\mathrm{a}} & \text { Arithmetic mean of departures from the mean line } \\ R_{\mathrm{p}} & \text { Maximum height of profile above the mean line } \\ R_{\mathrm{v}} & \text { Maximum depth of profile below the mean line } \\ \mathrm{S}-\mathrm{N} & \text { Stress life } \\ \mathrm{Wt} & \text { Weight } \\ \sigma_{\mathrm{f}}^{\prime} & \text { Fatigue strength coefficient } \\ \varepsilon_{\mathrm{f}}^{\prime} & \text { Fatigue ductility coefficient }\end{array}$

\section{Introduction}

Laser cut high strength steel grades can be used to generate flexible cuts of any geometry and form a clean cut with minimum damage [1]. It is through the use of the correct laser cutting parameters that can result in high-quality cutedges produced across a range of cutting speeds [2]. When using optimum process parameters, the advantages gained by using the laser are a small kerf width combined with the generation of only a narrow heat-affected zone (HAZ) [3]. The laser beam parameter is used to heat the steel and an oxygen assist gas jet exerts momentum onto the molten material, leading to formation of an exothermic reaction.

At low cutting speeds the heat flows into the material and dominates resulting is high energy absorption and resulting in a supplementary heat discharge. The most critical laser cutting process parameters in order of importance are (1) laser power, (2) traverse cutting speed, (3) assist gas pressure, and (4) the assist gas type. It is these parameters that significantly influence cut-edge quality during the laser cutting process $[4,5]$. 
Optimum laser cutting process parameters can produce a $0.1 \mathrm{~mm}$ degree of tolerance [6-12]. When using optimized laser process settings the cutting speed can be increased up to $5000 \mathrm{~mm} / \mathrm{min}$ [10]. By maintaining the same power then as the cutting speed is increased the kerf width decreases. It is the focusing of laser radiation, which is necessary for high-speed cutting [8]. The dominant process for different laser material processing techniques is as a function of laser energy and workpiece interaction. Here the cutting processes are divided into three classes, involving; (1) heating, (2) melting or (3) vaporizing the workpiece [9]. A significant proportion of heat is concentrated in the molten material and removed from the kerf via the pressurized assist gas [13]. The temperature distribution is localized in the thin cut-edge surface layer and the energy coupling at the workpiece surface is important in terms of determining the cut-edge microstructural properties [14].

Using high power intensity results in the beam being absorbed by the workpiece material, which can cause undesirable heating and vaporization of the workpiece material. Further problems such as workpiece distortion can also occur. The assist gas parameter interacts as a hydrodynamic process that melts the workpiece material and removes it through the bottom of the cut-edge. There are two types of assist gas used in laser cutting, reactive and non-reactive [15]. Reactive gases are used to cut low alloy steels, in which the reactive gas such as oxygen creates heat, leading to increases the thickness that can be cut and/or the cutting speed. Non-reactive gases are delivered at higher pressures in order to exert the necessary momentum on the liquefied material [16].

Numerous research studies have been conducted to examine the effect of assist gas during the laser cutting process. Experimental results showed that the use of oxygen as an assist gas resulted in better quality cut-edges than when nitrogen and argon are used to cut stainless steel [17]. When cutting mild steel then oxygen assist gas cutting produces the best cut-edge quality [18]. The use of oxygen as an assist gas at low traverse cutting speeds results in the formation of a wavy cut-edge. The size and properties of the HAZ are also of importance due to the high potential for local degradation leading to embrittlement of the cutedge. The increase of the kerf width further increases the size of striations formed on the cut-edge surface. Surface striations are primarily the cause for laser cut-edge roughness and are the paramount quality characteristic in laser cutting, and the formation of these features relates to both the cutting process and workpiece properties [19-21]. Surface properties are as a result altered, which have an effect on the fatigue life performance of cut-edges. Ensuring that minimum surface and microstructural damage is incurred then fatigue life can be improved over the life of the parent material [22].

\section{Experimental Methods}

\section{Material Properties}

The two high strength steels used in this study were selected; S355MC is a high strength low alloy (HSLA) steel grade and DP600 which is a dual phase, ferrite and martensite. The microstructures of these steels are shown in Fig. 1 and Table 1 presents the steel chemistry and mechanical properties.

\section{Laser Processing}

Laser cut-edges were generated using a Prima Industria Platino $1325 \mathrm{CO}_{2}$ laser. The cutting parameters used for generating laser cut-edges are shown in Table 2. For comparison milled edges, denoted as 'smooth' during this study, were generated using a Hardinge VMC600II CNC milling machine.

\section{Characterization}

Surface micrographs of laser cut-edges were captured using a Leica optical light microscope. Microstructural characterization and HAZ size measurements were analyzed through observing the specimens traverse to the cut-edge. Metallographic analysis of the near edge region microstructure was carried out by etching specimens using a $2 \%$ Nital reagent for $10 \mathrm{~s}$. The microstructures were observed using a Reichert Polyvar optical microscope. In order to record and quantify cut-edge surface properties, a Taylor-Hobson form 2 Talysurf was employed with scans being carried out across a two-dimensional surface area,

(a)

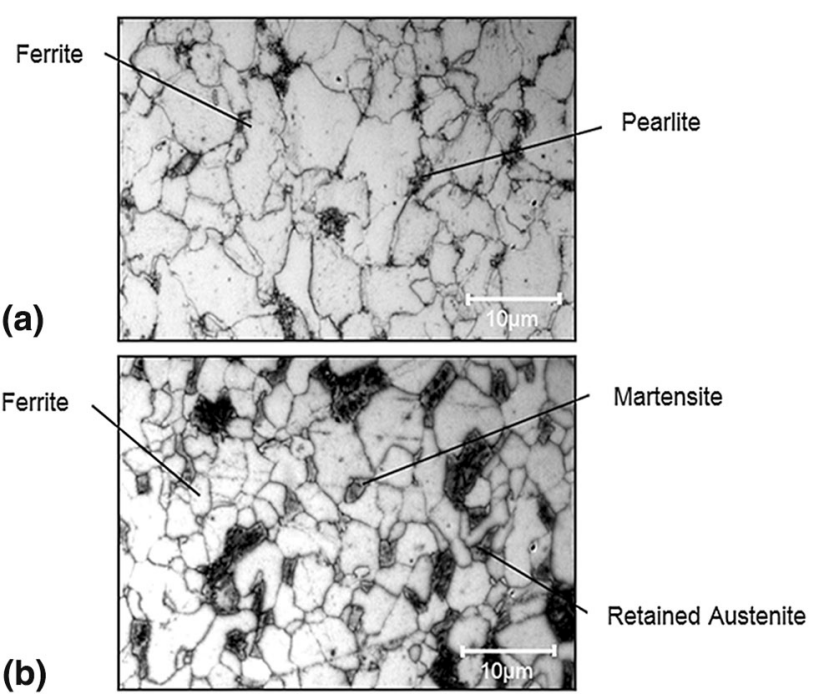

Fig. 1 Microstructure of S355MC and DP600 steels etched with 2\% nital 
Table 1 Steel chemistry as a weight percentage and mechanical properties of S355MC and DP600 steel grades

\begin{tabular}{|c|c|c|c|c|c|c|c|c|c|c|c|}
\hline \multirow[b]{2}{*}{ Grade } & \multicolumn{7}{|c|}{ Element composition (\%) } & \multicolumn{4}{|c|}{ Mechanical properties } \\
\hline & $\mathrm{C}$ & Mn & $\mathrm{Si}$ & $\mathrm{P}$ & $\mathrm{S}$ & $\mathrm{Al}$ & $\mathrm{Cr}$ & $\begin{array}{c}\text { Hardness } \\
\left(H_{\mathrm{v}}\right)\end{array}$ & $\begin{array}{c}\text { Yield strength } R_{\mathrm{p}} \\
\text { (MPa) }\end{array}$ & $\begin{array}{c}\text { Tensile strength } R_{\mathrm{m}} \\
(\mathrm{MPa})\end{array}$ & $\begin{array}{l}\text { Elongation } \\
\qquad \%)\end{array}$ \\
\hline S355MC & 0.067 & 0.591 & 0.020 & 0.019 & 0.007 & 0.043 & 0.022 & 157 & 393.86 & 472.83 & 30.8 \\
\hline DP600 & 0.087 & 1.089 & 0.189 & 0.043 & 0.005 & 0.037 & 0.569 & 237 & 475.11 & 690.70 & 21.5 \\
\hline
\end{tabular}

Table 2 The cut-edge test array, used for generating samples by means of a matrix of laser cutting process parameters

\begin{tabular}{lccccccc}
\hline Power $(\mathrm{W})$ & Cutting speed $\left(\mathrm{mm}^{-1}\right)$ & Assist gas & Pressure $(\mathrm{kPa})$ & Head stand-off $(\mathrm{mm})$ & Beam diameter $(\mathrm{mm})$ & Lens (inches) & Focus height $(\mathrm{mm})$ \\
\hline 800 & 1500 & Oxygen & 100 & 1.2 & 2.0 & 7.5 & 1.0 \\
2000 & 1500 & Oxygen & 100 & 1.2 & 2.0 & 7.5 & 1.0 \\
2000 & 4500 & Oxygen & 100 & 1.2 & 2.0 & 7.5 & 1.0 \\
\hline
\end{tabular}

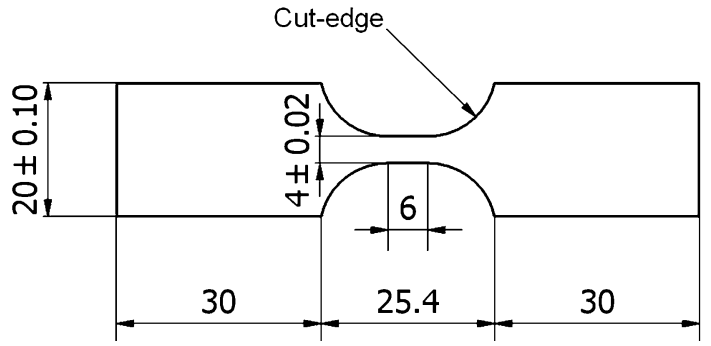

Fig. 2 Schematic of the fatigue specimen used during E-N and S-N fatigue testing

providing an accurate representation of the cut-edge roughness and waviness data parameters together with the generation of axonometric profiles. The degree to which the cut-edge surfaces had hardened was measured as Hardness Vickers $\left(H_{\mathrm{v}}\right)$ microhardness, and measurements were taken using a Leco M-400-G2 hardness tester with a $100 \mathrm{~g}$ load.

\section{Fatigue Life Testing}

Strain Life $(\mathrm{E}-\mathrm{N})$ fatigue testing was conducted using an Instron 8516 with a $50 \mathrm{kN}$ load cell and $30 \mathrm{kN}$ hydraulic grips in which the strain was controlled with a longitudinal extensometer; this testing was used to determine cyclic stress/strain curves.

Stress life ( $\mathrm{S}-\mathrm{N})$ fatigue testing was conducted using a Dartec $50 \mathrm{kN}$ servo-hydraulic testing machine with a K7500 controller and the stress was controlled using a $30 \mathrm{kN}$ load cell. All S-N life tests were carried out using a stress ratio of $R=-1$ at a frequency of $30 \mathrm{~Hz}$. Stress life fatigue tests that ran to $1 \times 10^{7}$ cycles were considered to be run out tests. These fatigue data were compared with milled fatigue specimens denoted as smooth, which was used to determine the difference in the fatigue lives of cut-edges in comparison with smooth data. The semi-circle geometry of the fatigue specimen as shown in Fig. 2 was cut using the laser process parameters detailed in Table 2, respectively, with the remainder of the specimen being polished.

\section{Durability Performance}

Beam structures as shown in Fig. 3 were manufactured to include an 85.0 and $12 \mathrm{~mm}$ laser cut-edge hole, which was generated using the same cutting process parameters that were used to make the fatigue coupon specimens.

These structures were four-point bend loaded, using a Dartec $250 \mathrm{kN}$ hydraulic testing machine, in which testing was conducted using a sinusoidal wave $4 \mathrm{~Hz}$ loading cycle with a stress ratio of $R=0.1$, for maximum fatigue loads of $20,22,24,26$, and $28 \mathrm{kN}$. The distribution of stress around the cut-edge is at its highest at the center of the structure, and this is the area where all fatigue cracks were observed to initiate. Spit welding was carried out using an A1 AC Electric spot welding system using swan neck electrodes to produce nineteen spot welds down each side of the flange.

Each structure was visually checked for the initiation and growth of a small visible crack to $0.5-1.0 \mathrm{~mm}$ in length at the apex of the cut-edge hole at intervals of 2000 cycles, and the number of cycles reaching this point was defined as the life to crack initiation.

\section{Strain Gage Loading Testing}

Strain measurements were carried out using strain gages that were placed at a number of positions in specific 
Fig. 3 Beam structure with exposed laser cut-edge at the apex of the beam member
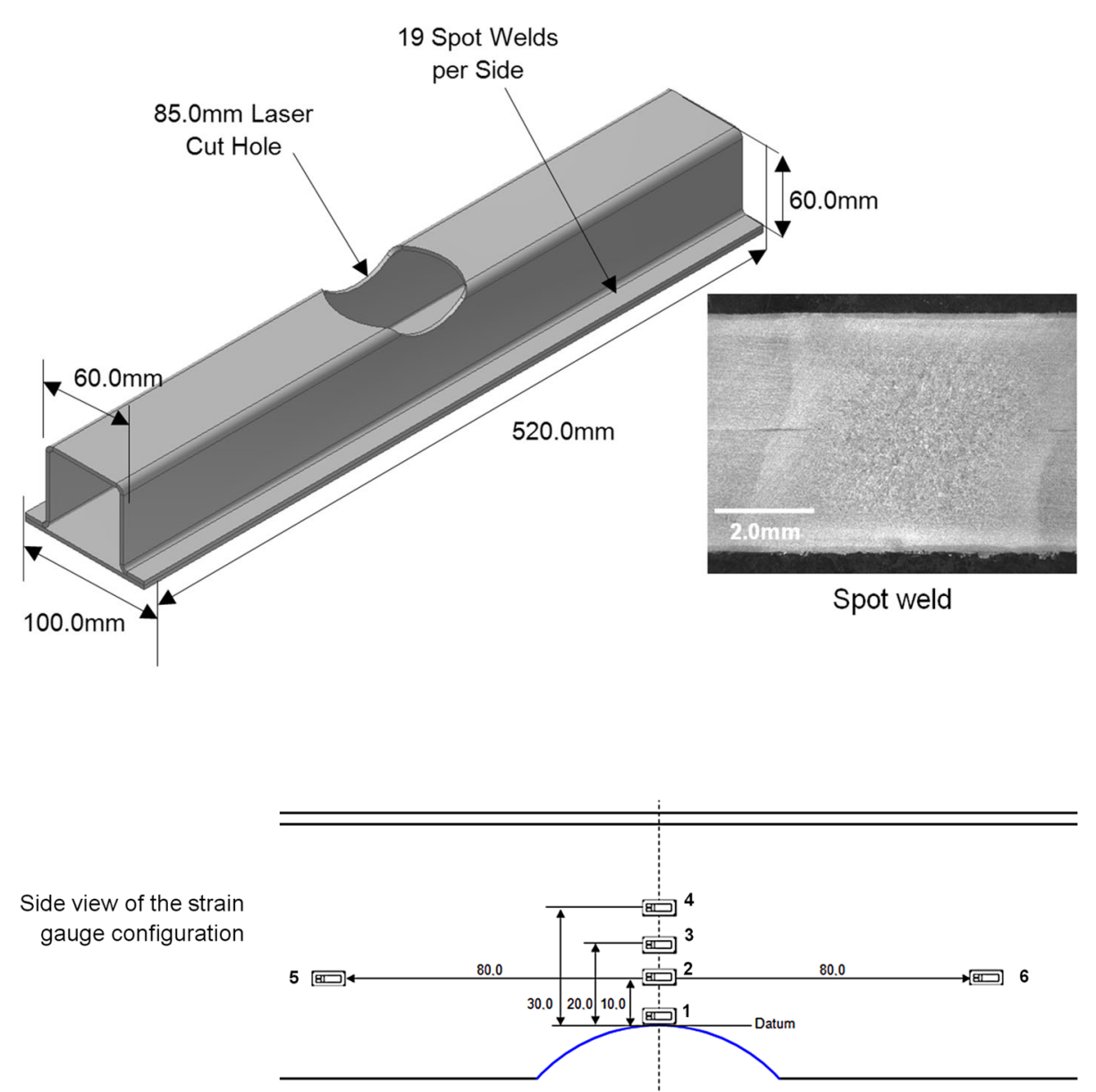

ide view of the strain gauge configuration
Fig. 4 Schematic of the strain gage measurement positions taken from around the cut-edge hole regions around the cut-edge hole as shown in Fig. 4. The physical strain was measured so that comparisons could be made with the FE-based strain predictions. The static strain measurements were taken in microstrains using Vishay EA-06-125BZ-350, Quarter Bridge strain gages attached to one side of a Beam structure at strategic locations around the cut-edge hole using standard M-Bond 500 adhesive with curing carried out at room temperature. Testing was carried out on a single Beam structure that was loaded using 18.0, 20.0, 22.0, 24.0, and $26 \mathrm{kN}$. The strain was measured at each of the loads using the Vishay System 5000 in which unloading took place before the next load was applied.

\section{Finite Element Analysis}

A FE model of the Beam component was created using a general-purpose Finite Element (FE) pre-processor Hypermesh. This structure was produced to represent the sheet steel by using four-noded quadrilateral elements with an element size of $0.5 \mathrm{~mm}$. This was the baseline FE model that was used to predict and later compare the fatigue performance of the physical structures. Load and boundary conditions were applied to simulate the fatigue loading and fixing of the structure on the four-point loading rig. There are 6 degrees of freedom in the model that were fixed at either end of the structure with loading and support points being applied. FE stress analysis was performed using MSC.Nastran and the results were imported into MSC.Partran, which produced stress contour maps. The analysis is important in terms of observing the stress distribution under an applied load. Comparisons of this region were made with that of the physical components strain gage measurements. This was to ensure that the FE predictions were comparable to that of the actual result, and this stress analysis becomes an increasingly important component when determining the fatigue life. FEbased fatigue life analysis software MSC.Fatigue was used to estimate the fatigue damage and lives to crack initiation at the cut-edges, for the actual applied fatigue loads. The FEbased fatigue analysis was based on the principle of stress scaling and super-positioning with plasticity correction using Neuber's rule, where required. 


\section{Results and Discussion}

\section{Cut-Edge Surface Characteristics}

Laser cut-edges generated using different process parameters produce a characteristic surface features. This is coupled with internal metallurgical transformations in the near edge region. These properties are dependent on the process parameters used during the cutting process as shown in Fig. 5. In comparison between each steel grade, it was apparent that deeper striations occurred in the DP600 material, and this is due to an increase in cut-edge surface melting as a result of the higher silicon content in the steel. Silicon reacts with the oxygen assist gas and increases the viscosity of the molten steel during the cutting process. As a result there is further melting of the DP600 steel structure.

As the traverse cutting speed was increased it was observed that the formation of striations at the bottom of the cut-edges became less pronounced. The striations became finer and closer together at the top of the cut-edge as the traverse cutting speed was increased. As the laser power is increased the striations became more distinctive because of the increased energy coupling. As the traverse cutting speed was increased to compensate then the striation became less distinctive. Observations signified that both the frequency and definition of surface striations are particularly apparent at high power settings.

Striations running parallel to the lasers cutting direction were particularly visible at high cutting speeds and even more so when the power was increased. As it has been previously argued, the cut-edge surface provides a paramount means of assessing the quality of laser cut-edges from an industrial processing context, in the first instance. The generation of laser cut-edges used oxygen as an assist gas, so as to achieve high cutting speeds with an efficient use of power, which is exceptionally important in terms of achieving high levels of throughput from a manufacturing context.

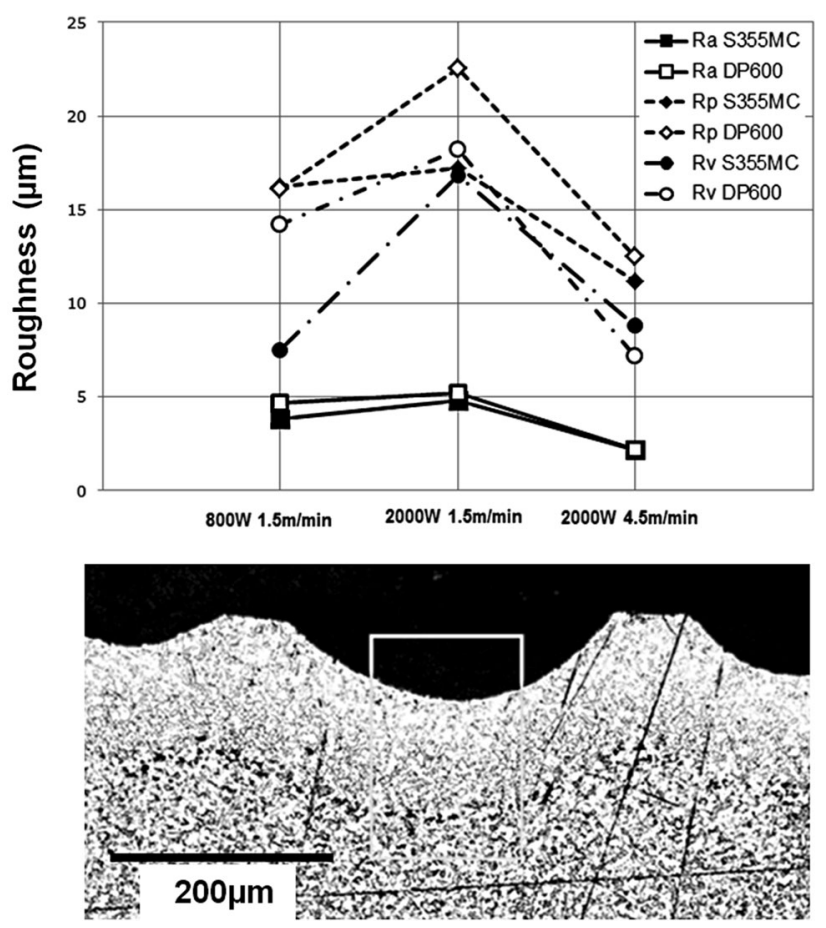

Fig. 6 Laser cut-edge surface roughness profiles of S355MC and DP600 laser cut-edges generated using different processing parameters, showing the critical $R_{\mathrm{a}}, R_{\mathrm{p}}$, and $R_{\mathrm{v}}$ surface roughness parameters. Micrograph of the traverse properties of a laser cut-edge striation geometry

S355MC

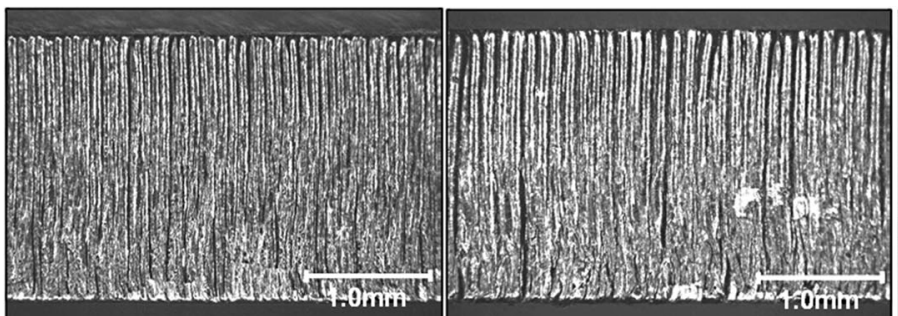

Power $800 \mathrm{~W}$ Speed $1.5 \mathrm{~m} / \mathrm{min}$

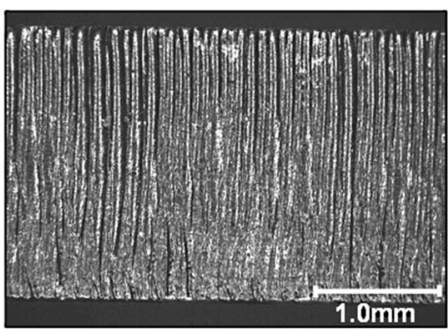

Power $800 \mathrm{~W}$ Speed $1.5 \mathrm{~m} / \mathrm{min}$
Power 2000W Speed $1.5 \mathrm{~m} / \mathrm{min}$

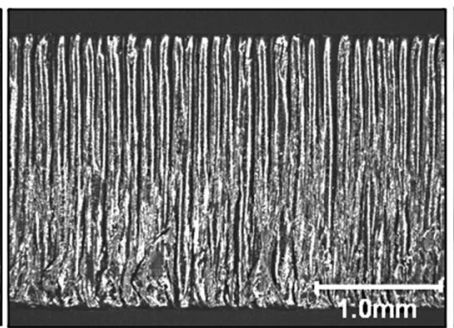

Power 2000W Speed $1.5 \mathrm{~m} / \mathrm{min}$

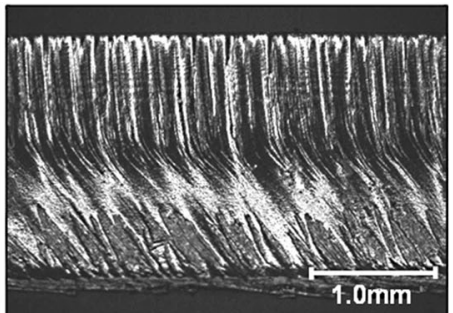

Power 2000W Speed $4.5 \mathrm{~m} / \mathrm{min}$

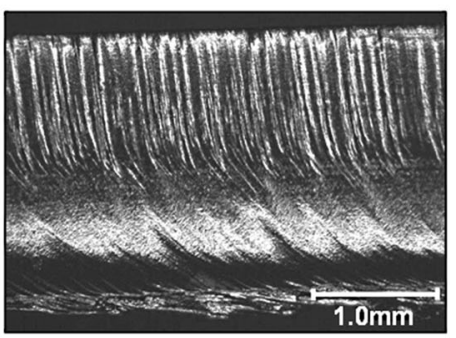

Power 2000W Speed $4.5 \mathrm{~m} / \mathrm{min}$

Fig. 5 Micrographs and axonometric profiles of laser cut-edge surfaces of S355MC and DP600 


\section{Surface Topographical Characteristics}

The top down patterns of surface striations when using different process parameters are shown in Fig. 6. The periodic formation of surface striations produced when using high applied power was characteristically different with inconsistent striations produced.

The surface roughness profiles of the laser cut-edges were observed to be only the slight formation of surface peaked features across the range of processing parameters. The trends shown by each roughness parameter $\left(R_{\mathrm{a}}, R_{\mathrm{p}}\right.$, and $\left.R_{\mathrm{v}}\right)$ are consistent for both steels. The surface roughness properties of laser cut-edges were observed to be influenced by the laser process parameters applied. As the ratio of power to traverse cutting speed was increased, this resulted in additional melting of the material and thus a higher surface roughness. Then as the traverse cutting speed was increased between to compensate for the high power utilized, surface roughness decreases once again. The $R_{\mathrm{p}}$ and $R_{\mathrm{v}}$ surface roughness values are used to establish the properties of laser surface striations with the optimum pattern indicated by a minimum difference between $R_{\mathrm{p}}$ and $R_{\mathrm{v}}$ properties. An observation was that DP600 was slightly more sensitive towards the influence of induced surface disruptions during the laser cutting process.

\section{Microstructural Properties}

A relationship was observed that laser cut-edges generated using high power to traverse speed ratio resulted in harder cut-edge surfaces. Due to metallurgical alterations in the HAZ of the cut-edge, there is a change in the measured transverse surface hardness. In each steel grade, the result of increasing the traverse cutting speed had little effect on influencing the surface hardness. At $800 \mathrm{~W}$ this resulted in the formation of comparably softer cut-edge surfaces. These results are quantified in Fig. 7, in which the $H A Z$ was observed to have become thicker towards the bottom of the cut-edge across the full range of traverse cutting speeds.

Figure 8 shows the measured thickness of the HAZ for each steel grade. The HAZ thickness is critical towards not only in determining the quality of the cut-edge, but also in ascertaining the depth of the metallurgical alterations that have occurred. It is the process of controlling the heating, melting and cooling during the laser cutting process that is critical towards generating the minimum heat-affected damage to the workpiece, which occurs when using a low power and low traverse cutting speed.

At the traverse cutting speed of $1.5 \mathrm{~m} / \mathrm{min}^{-1}$ the HAZ size was $0.1 \mathrm{~mm}$ wider when using $2000 \mathrm{~W}$ in comparison with using $800 \mathrm{~W}$ in the case of S355MC. However, there was little difference between the HAZ width across the range of process parameters when cutting DP600 steel. The HAZ thickness measurements indicated a relationship between HAZ size and cut-edge hardness. The bottom of laser cut-edges was harder and the HAZ thickness was also wider than the top.

There was measured to be a fine transition boundary between the heat-affected material and the parent
Fig. 7 S355MC and DP600 transverse surface hardness profiles $0.1 \mathrm{~mm}$ from the laser cut surfaces

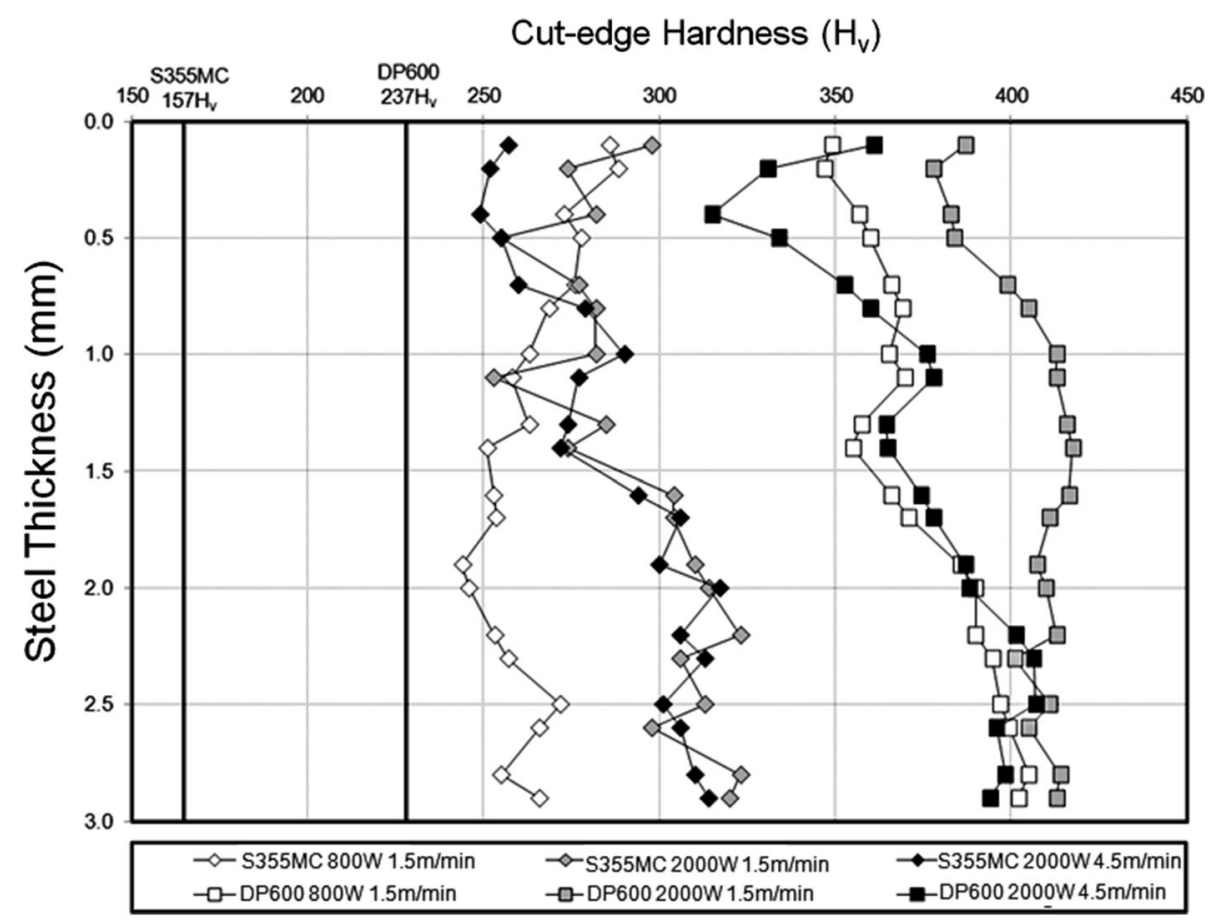




\section{HAZ Thickness (mm)}

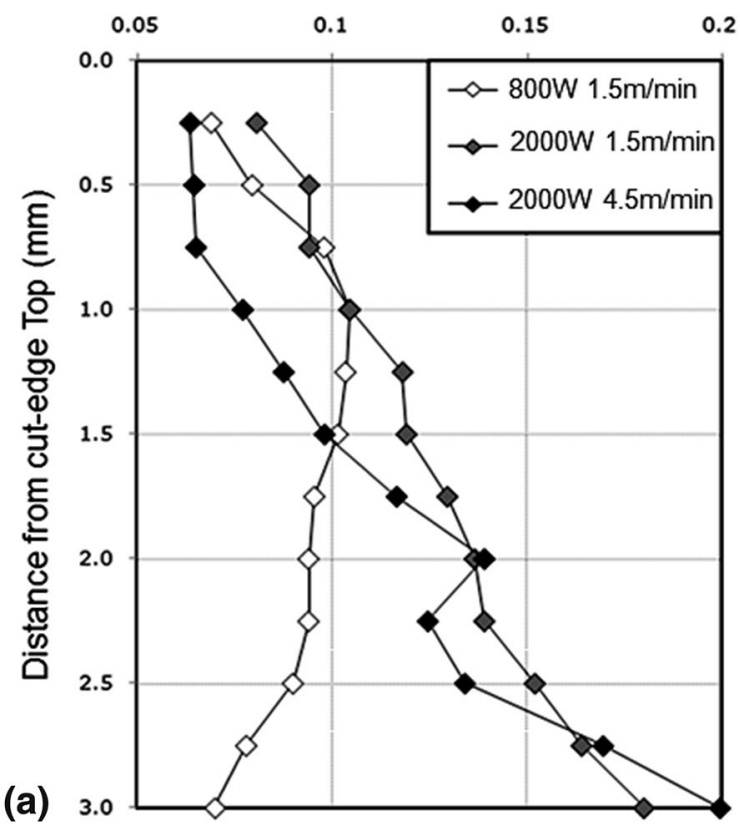

HAZ Thickness $(\mathrm{mm})$

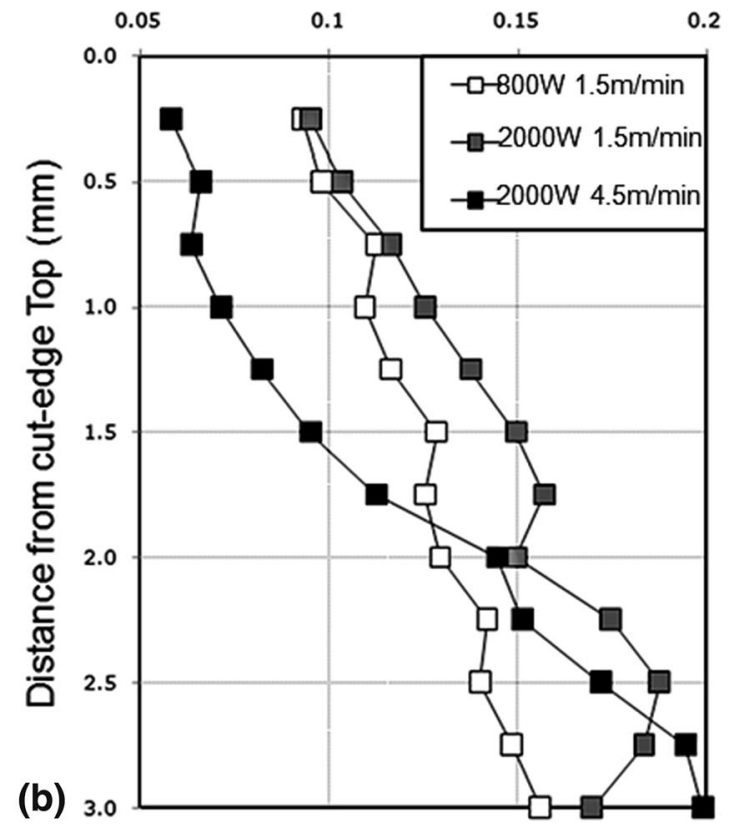

Fig. 8 HAZ width throughout the thickness of (a) S355MC and (b) DP600 laser cut-edges

microstructure. The martensitic region close to the cutedge is phase transformed material of the heat-affected zone. The material is brittle phase transformation of the metallographic structure and the transformation of the parent material microstructure to a Martensitic structure.

\section{Laser Cut-Edge Fatigue Lives}

The stress life (S-N) fatigue curves of the different laser cutedges of S355MC are shown in Fig. 9. In Laser cut-edges, it was observed that there was an improvement in the fatigue live under high stress for cut-edges generated using $2000 \mathrm{~W}$ and $1.5 \mathrm{~m} / \mathrm{min}$ process parameters (Fig. $9 \mathrm{~b}$ ). This was also the case for cut-edges generated using $2000 \mathrm{~W}$ and $1.5 \mathrm{~m} /$ min process parameters in which there was a slight increase in the fatigue life across the full range of stresses (Fig. 9a). This is particularly seen under low stress loading which displayed a slight increase in fatigue life. However, when using $2000 \mathrm{~W}$ and $4.5 \mathrm{~m} / \mathrm{min}$ process parameters this resulted in a significant decrease in the fatigue life by a factor of 25 at an applied stress of $550 \mathrm{MPa}$ (Fig. 9c).

It was observed that in the case of DP600 there were slight decreases in fatigue performance across the range of process parameters as shown in Fig. 10. There was a slight decrease in the fatigue life by $15 \%$ when using $800 \mathrm{~W}$ and $1.5 \mathrm{~m}$ (Fig. 10a). When using $2000 \mathrm{~W}$ and $4.5 \mathrm{~m} / \mathrm{min}$, there is a dramatic decrease in the fatigue life by a factor of 4.5. This is not as significant as was found in the case of S355MC.
The comparison of strain life fatigue curves of smooth with the optimum laser cut-edge process setting of S355MC is shown in Fig. 11. These cuts were generated using $800 \mathrm{~W}$ and $1.5 \mathrm{~m} / \mathrm{min}$. It was observed that the strain life of laser cut-edges showed no significant difference over that of smooth edges under low strain. However, at higher strain amplitudes there was a significant drop in the number of reversals to failure when compared with smooth edges, with a decrease in life by a factor of 3 at a strain of 0.008 . This is indicative of a possible induced localized plastic deformation in the base of a laser striation under higher applied strain and subsequent premature failure of the specimen.

The comparison of strain life fatigue curves of smooth with the optimum laser cut-edge process parameters of DP600 is shown in Fig. 12. It was observed that the elastic strain of laser cut-edges showed a slight decrease in performance over that of smooth edges. The influence of a higher strain on the number of reversals to failure of DP600 laser cut-edges was not as significant as it was for S355MC.

\section{Component Structural Loading}

Each specimen was tested using a process of symmetrical four-point sinusoidal loading as shown schematically in Fig. 13. During the process of four-point bend loading, stress was nominally applied equally to each side of the Beam structures cut-edges. For the form of analysis in this 

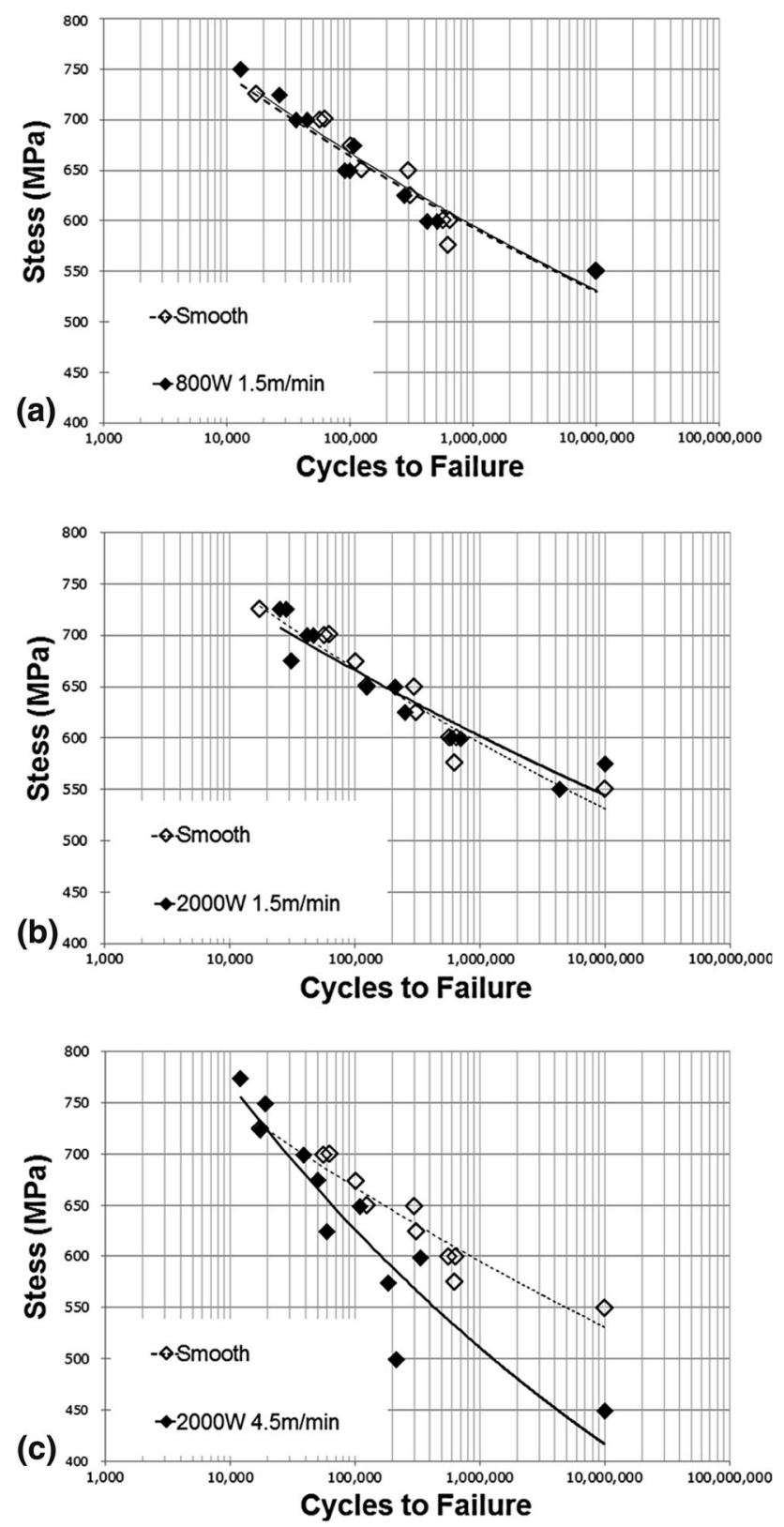

Fig. 9 S-N fatigue curves of S355MC laser cut-edges in comparison with smooth edges using (a) $800 \mathrm{~W}$ and $1.5 \mathrm{~m} / \mathrm{min}$ (b) $2000 \mathrm{~W}$ and $1.5 \mathrm{~m} / \mathrm{min}$ and (c) $2000 \mathrm{~W}$ and $4.5 \mathrm{~m} / \mathrm{min}$, process parameters

research, the apex of cut-edge hole region is the area of most significance and is observed for the formation of fatigue cracks during the sinusoidal four-point loading process.

Under static loading of the beam displacement has a linear relationship with the applied load up to $32 \mathrm{kN}$. Above this, the components load-displacement relationship becomes non-linear. This indicates the occurrence of significant material yielding and plastic deformation, until there is a complete loss of structural integrity at a maximum load of approximately $45 \mathrm{kN}$.
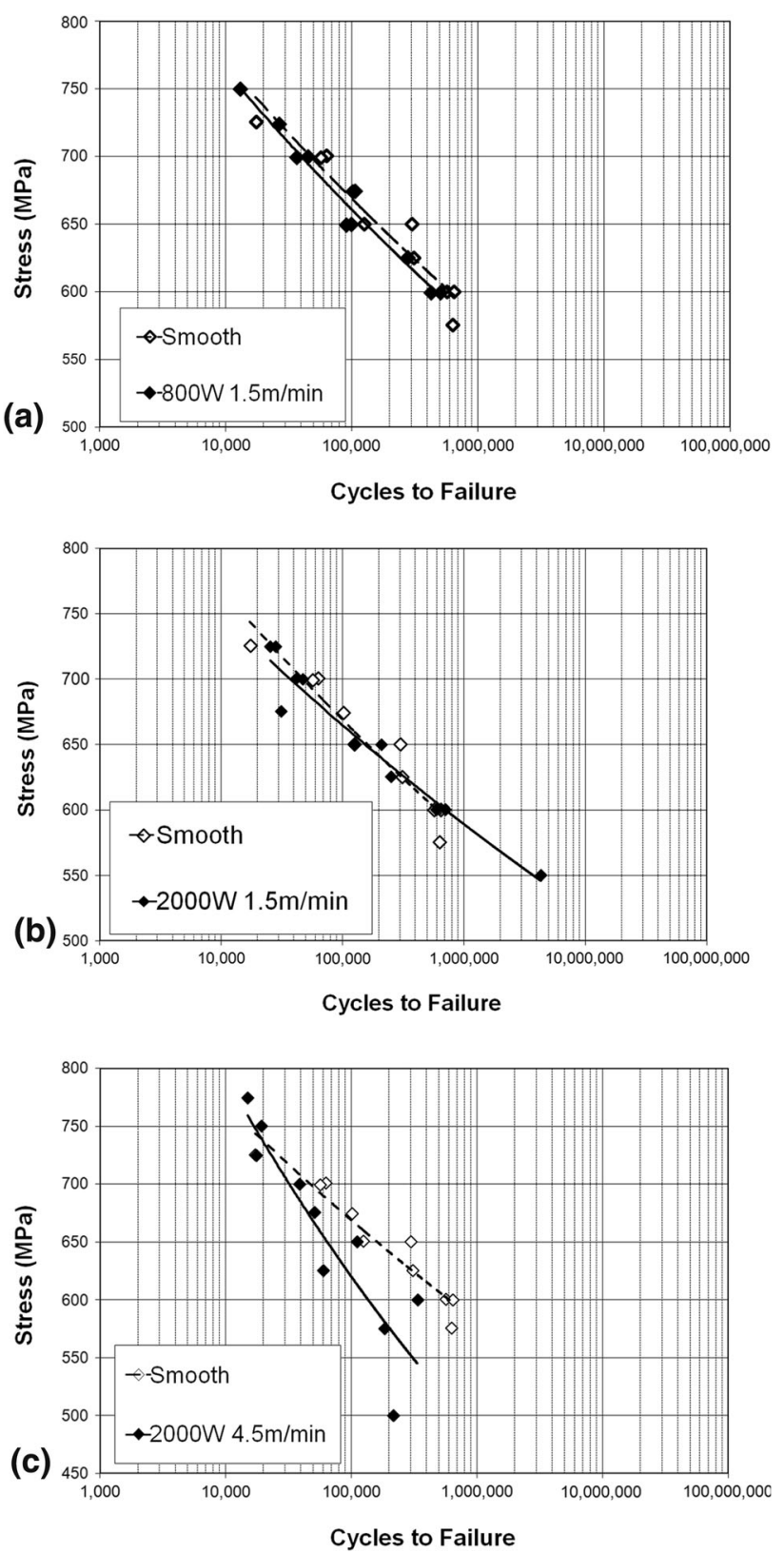

Fig. 10 S-N fatigue curves of DP600 laser cut-edges in comparison with smooth edges using (a) $800 \mathrm{~W}$ and $1.5 \mathrm{~m} / \mathrm{min}$ (b) $2000 \mathrm{~W}$ and $1.5 \mathrm{~m} / \mathrm{min}$ and (c) $2000 \mathrm{~W}$ and $4.5 \mathrm{~m} / \mathrm{min}$, process parameters

The results of the physical strain measurements against those of the predicted FE strain are shown in Fig. 14. FE strain predictions of the regions around the cut-edge hole were reasonably similar to those when measured physically. It can be seen that in the more critical cut-edge edge regions as indicated by gages 1 and 2 the physical measured strain is slightly lower than the model prediction particularly under lower loads. At a region $30.0 \mathrm{~mm}$ from the edge as indicated by strain gage 3 , there was a far lower level of actual strain in comparison with the prediction and suggests that the distribution of strain around the cut-edge region is more localized. 
Fig. 11 E-N fatigue performance of S355MC edges cut using $800 \mathrm{~W}$ and $1.5 \mathrm{~m} / \mathrm{min}$ cutting speed against smooth edge data
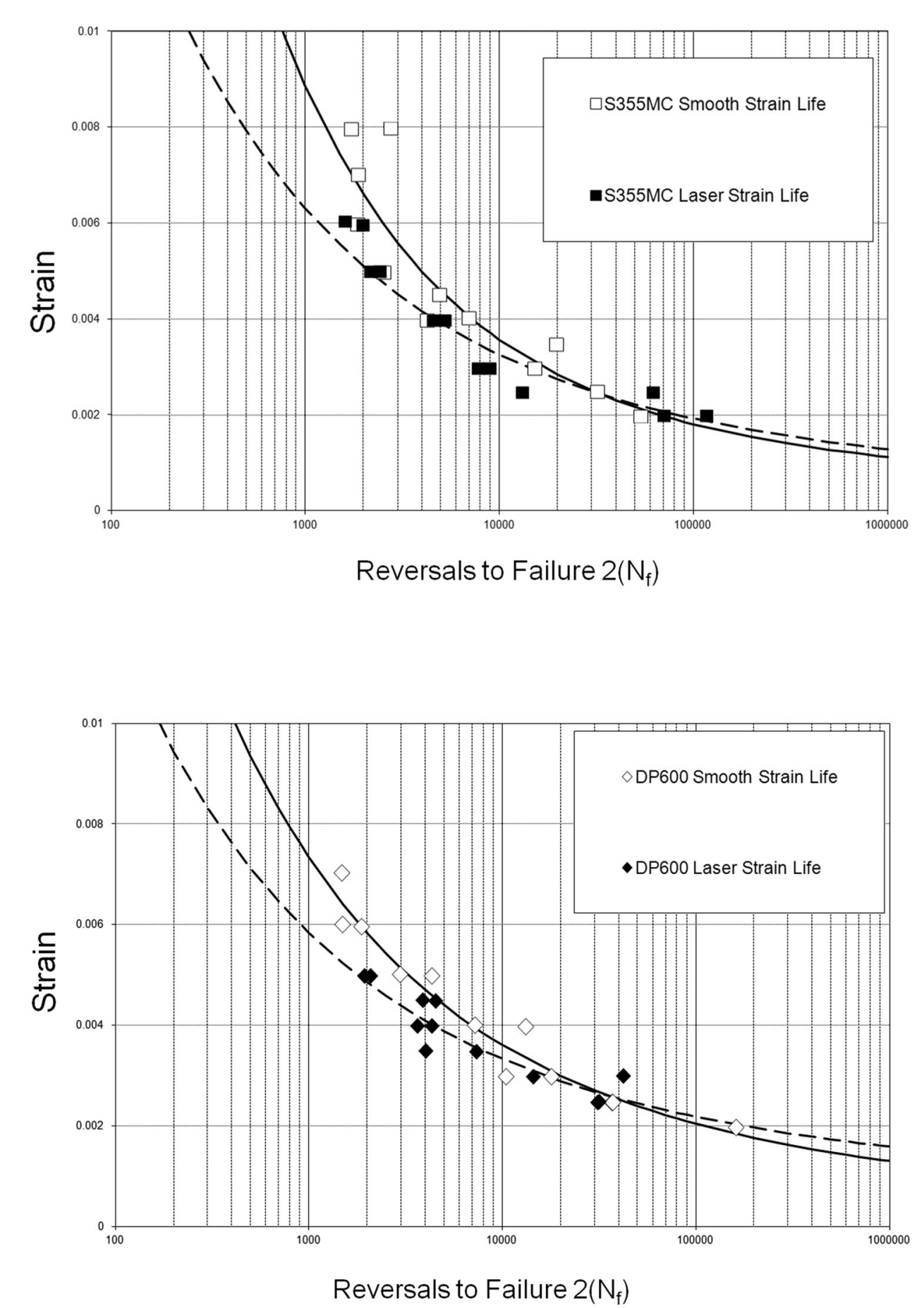

Reversals to Failure $2\left(\mathrm{~N}_{\mathrm{f}}\right)$
Fig. 12 E-N fatigue performance of DP600 edges cut using $800 \mathrm{~W}$ and $1.5 \mathrm{~m} / \mathrm{min}$ cutting speed against smooth edge data
The $R=0.1$ loading carried out on Beam structures is more rigorous as the cut-edge is always in tension. This resulted in a lower number of cycles to crack initiation and subsequent component failure.

The same trend was observed when comparing the strain results measured. These results suggest that due to a slight unsymmetrical loading under real testing there will be a difference in the stress distribution. It is this factor which could also influence the actual prediction comparison; in that the model is always applying the loads precisely when FE predictions are made. Based on these strain results it appeared that the critical gages 1 and 2 had a reasonable correlations with FE analysis results, particularly under higher applied loads.

Beam structural loading, optimum laser cut-edges generated on S355MC and DP600 using $800 \mathrm{~W}$ and 

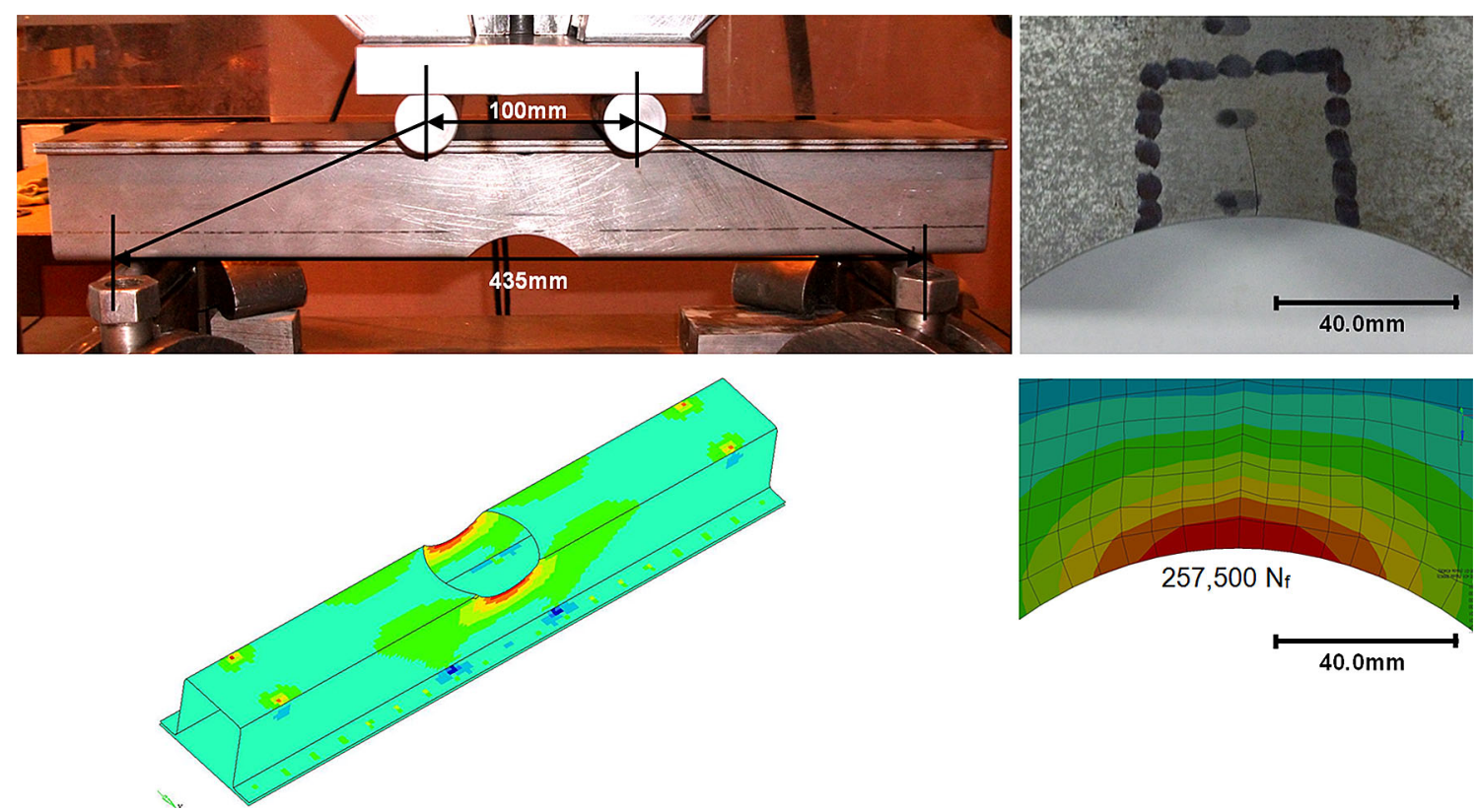

Fig. 13 Beam structure under the process of sinusoidal wave four-point loading and the distribution of stress around the apex of the cut hole. The critical apex of the structure is the location of maximum stress from where a fatigue crack initiate

\section{FE Strain Prediction}

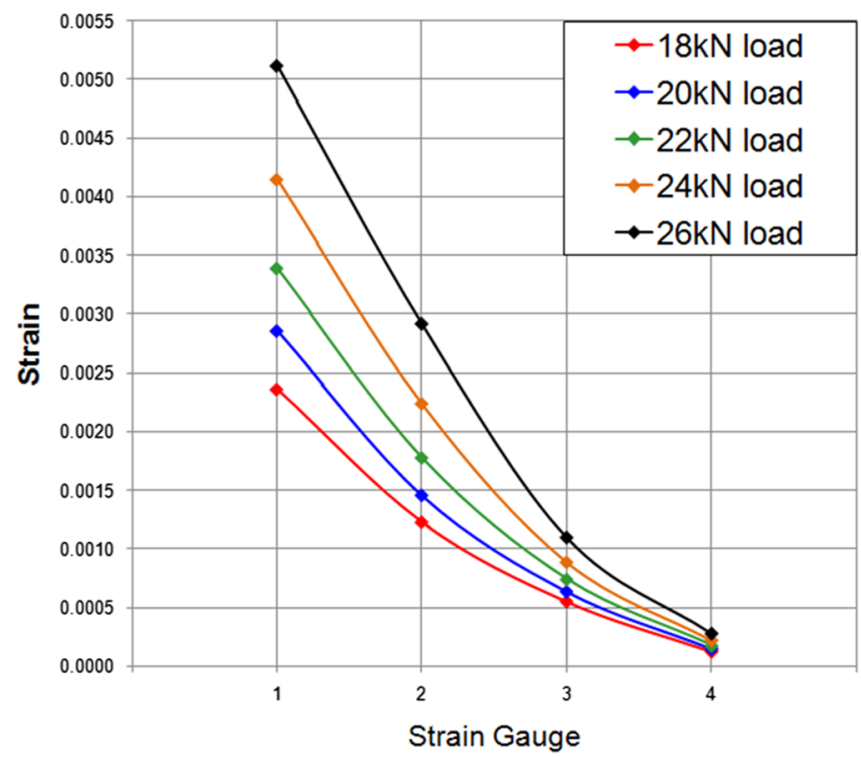

Real Strain

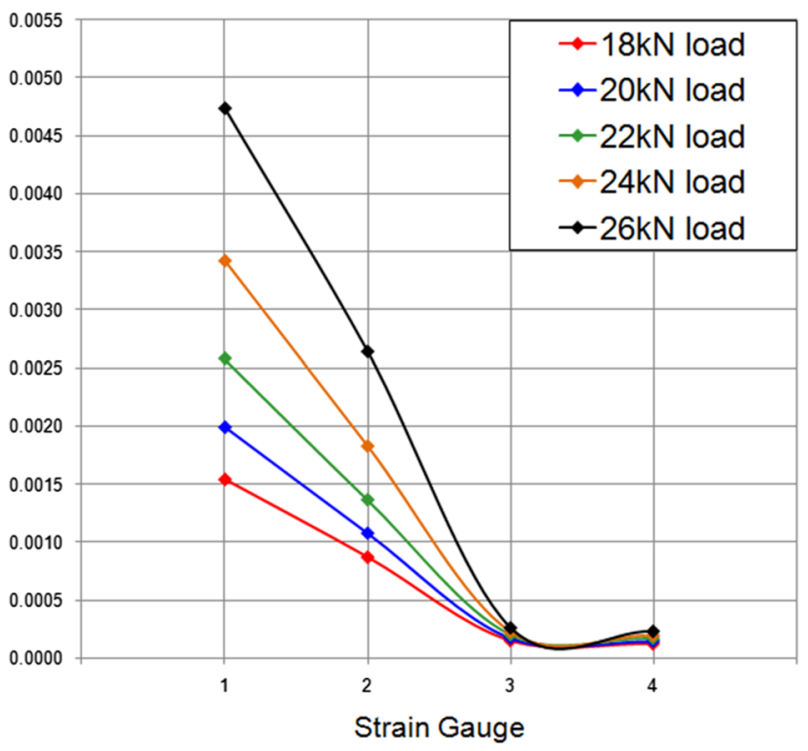

Fig. 14 Comparison of the strains measures taken by gages 1-4 under the different applied loads (kN) and the FE model prediction

$1.5 \mathrm{~m} / \mathrm{min}$ traverse cutting speed are shown in Figs. 15 and 16, respectively. In the case of S355MC, towards the high stress loading regime, the fatigue life of the structure was extended by $30 \%$ over smooth cut-edge. This difference became of less significance under high cycle fatigue (HCF) over 200,000 cycles in which the lives of laser cut-edges were near to the same as that of smooth edges (Fig. 17).
The fatigue life of DP600 steel became extended by up to five times that of smooth cut-edges under HCF loading. These results indicate that the lives of laser cut-edges can be used to extend and significantly improve the life of the application. Figure 18 shows the formation of a fatigue crack from an S355MC cut-edge under $24 \mathrm{kN}$ loading. The resulting crack formation shows that the initiation point is at the trough of a striation. 
The resulting crack formation appears brittle in characteristic and has resulted in rapid crack growth. Observations of the fatigue crack indicate that it started as a brittle

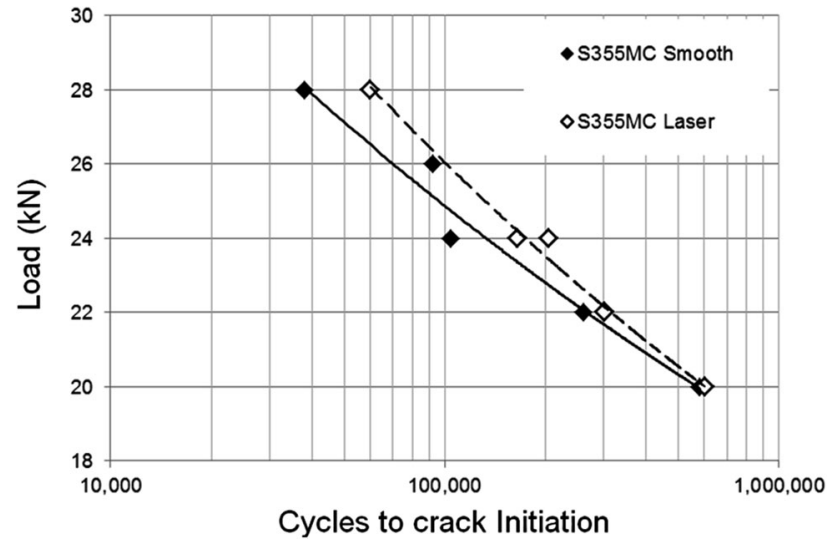

Fig. 15 Crack initiation lives under four-point loading of the beam from S355MC laser cut-edges in comparison with smooth cut-edges

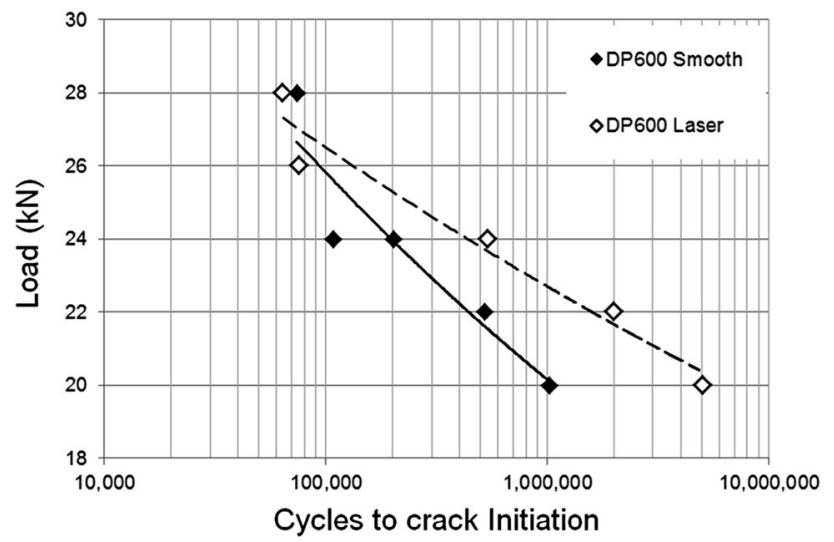

Fig. 16 Crack initiation lives under four-point loading of the beam structure from DP00 laser cut-edges in comparison with smooth cutedges initiation within the HAZ before propagating through to the more ductile parent microstructure. The fatigue fracture surface of the cut-edges fatigue crack propagating from a laser cut-edge revealed that initiation was observed to start from the lower region of the cut-edge. As it was observed when testing fatigue coupons, the definition of laser striations is also critical towards determining the fatigue performance of a larger component. Macroscopically two distinct zones were present on the fracture surface, and the region I crack growth is comparatively smooth. The region II crack growth consisted of a coarse beach lines forming during crack growth and these features became coarser with increasing fatigue crack length.

\section{CAE-Based Assessment of Durability}

The important region of node elements around the hole is shown in Fig. 19 and represents the critical cut-edge region. This is defined as an edge element versus edge quality lookup data for interpolation, from the data collected during the testing of fatigue coupons with smooth and laser cut-edges. FE stress analysis was performed using MSC.Nastran and the results were imported into MSC.Partran, which produced stress contour maps. The analysis is important in terms of observing the stress distribution under an applied load. Comparisons of this region were made with that of the physical components strain gage measurements. This was to ensure that the FE predictions were comparable to that of the actual result, and this stress analysis becomes an increasingly important component when determining the fatigue life. Under the process of four-point loading, the stresses radiate from around the cut-edge hole during the process of four-point loading, with the peak stress being at the apex of the cutedge hole.
Fig. 17 Fatigue crack initiation from an S355MC laser cut-edge under $24 \mathrm{kN}$ loading (a) top profile of the fatigue crack, and (b) crack fracture surface
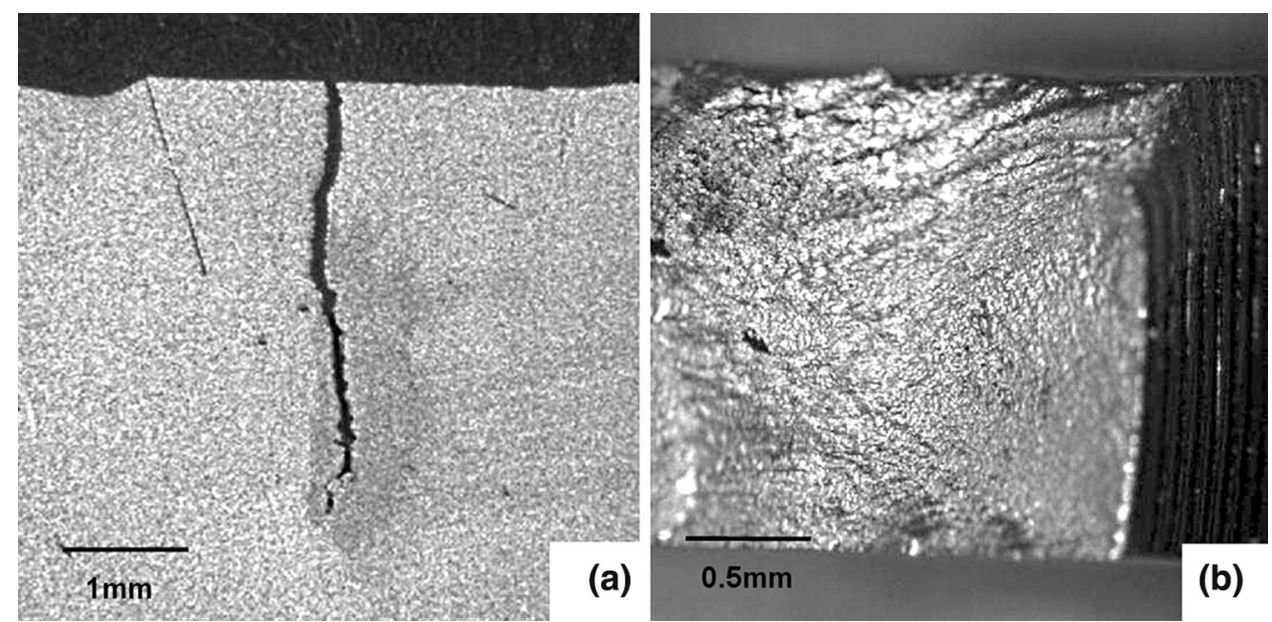


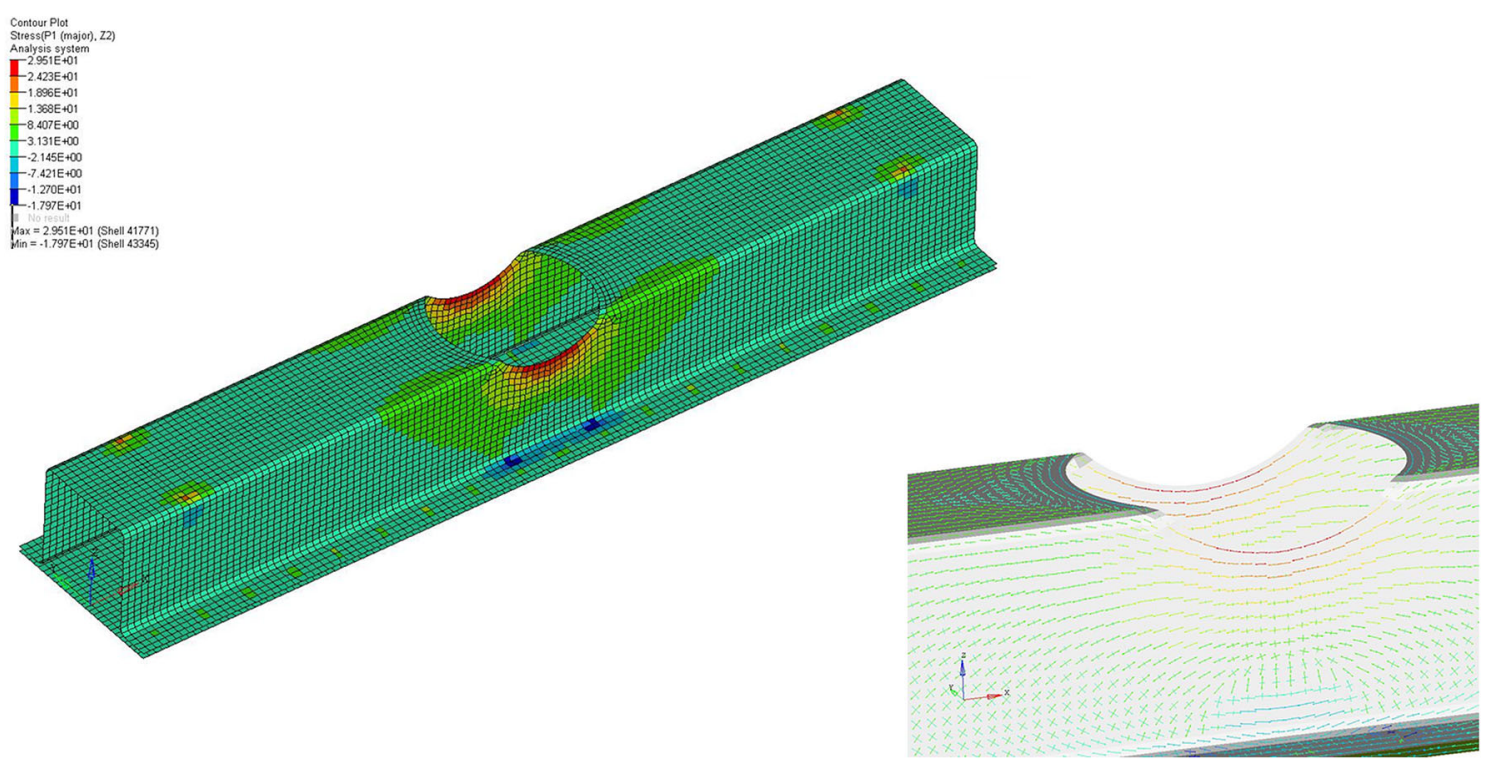

Fig. 18 Stress distribution produced around the cut-edge hole under loading showing the FE model of the region around the cut-edge principal stress and tensor stresses
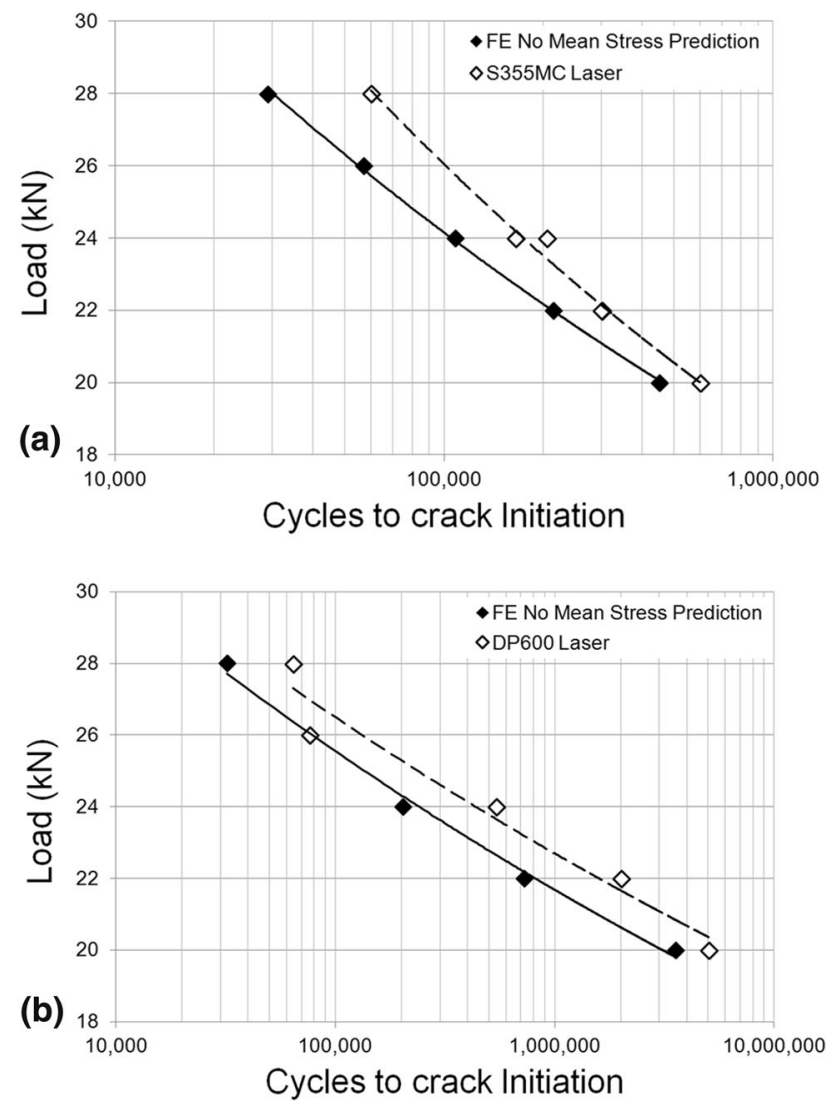

Fig. 19 Fatigue life FE predictions compared with physical smooth cut-edge data of (a) S355MC and (b) DP600 laser cute-edges

The physical results were compared with those of the FE model predictions, in which the linear-elastic strain prediction made by the model was calculated at $1 \mathrm{kN}$. The component displacement is at its maximum at the apex of the cut-edge holes radius and this increased as the applied load was increased. The area of maximum stress at the center of the structure was also where fatigue cracks were observed to initiate under the sinusoidal loading process. Because of the geometry of the structure, there is an area of stress concentration at the center, forming a localized plastic zone. This stress concentration is therefore critical towards determining the resulting fatigue lives of the structures with laser cut-edges.

It is this understanding of the materials response during the loading process that is critical towards being able to make accurate FE life prediction for fatigue crack initiation lives of laser cut-edges. Predicting the lives to crack initiation through FE analysis is based on the use of E-N cut-edge fatigue coupon data, in which predictions were made using the MSC.Fatigue data analysis module within MSC.Nastran

The material data and $\mathrm{E}-\mathrm{N}$ fatigue data of the different cut-edges as shown in Table 3 were used to make the fatigue life FE model predictions of the Beam structure under loading. These data were inserted into a database that was used in analysis to extrapolate fatigue life curves of the structure using three methods of prediction to evaluate fatigue lives to crack initiation.

There are two specific elements to make fatigue life predictions; the first is based on the physical data gathered as shown in Figs. 8, 9, and 10. Following this, comparison with the strain life method is the most conventional and is based on a zero mean stress Coffin-Manson relationship, as shown in (Eq 1). 
Table 3 Cut-edge tensile, E-N fatigue and cyclic stress strain coefficient data used in the model prediction

\begin{tabular}{|c|c|c|c|c|c|c|c|c|c|c|}
\hline \multirow[b]{2}{*}{ Material and cut-edge } & \multicolumn{4}{|c|}{ Monotonic/tensile data } & \multicolumn{6}{|c|}{$\begin{array}{l}\text { Strain-life fatigue (Coffin-Manson) coefficients and cyclic stress-strain } \\
\text { coefficients }\end{array}$} \\
\hline & $E(\mathrm{MPa})$ & $R_{\mathrm{p} 0.2}(\mathrm{MPa})$ & $R_{\mathrm{m}}(\mathrm{MPa})$ & $A_{80}(\%)$ & $\sigma_{\mathrm{f}}^{\prime}(\mathrm{MPa})$ & $b$ & $\varepsilon_{\mathrm{f}}^{\prime}$ & $c$ & $K^{\prime}$ & $n^{\prime}$ \\
\hline S355MC Smooth & 207,000 & 393.86 & 472.83 & 30.8 & 1133.34 & -0.13156 & 0.51144 & -0.60978 & 1053.67 & 0.18415 \\
\hline S355MC Laser & 207,000 & 393.86 & 472.83 & 30.8 & 893.12 & -0.10372 & 0.12072 & -0.47101 & 1280.87 & 0.20852 \\
\hline DP600 Smooth & 207,000 & 475.11 & 690.70 & 21.5 & 1561.35 & -0.14469 & 0.13762 & -0.48316 & 2026.71 & 0.24957 \\
\hline DP600 Laser & 207,000 & 475.11 & 690.70 & 21.5 & 2339.23 & -0.19001 & 0.07798 & -0.44596 & 1451.33 & 0.18815 \\
\hline
\end{tabular}

Table 4 Fatigue lives to initiation of real physical data compared with FE-based 'no mean stress predictions' of S355MC and DP600 laser cutedges

\begin{tabular}{|c|c|c|c|c|c|c|c|}
\hline \multicolumn{4}{|c|}{$\mathrm{S} 355 \mathrm{MC}$} & \multicolumn{4}{|c|}{ DP600 } \\
\hline Max load $(\mathrm{kN})$ & $\begin{array}{c}N_{\mathrm{f}} \text { FE prediction } \\
\text { Life }\end{array}$ & $\begin{array}{c}N_{\text {f }} \text { real laser } \\
\text { Life }\end{array}$ & $\frac{N_{\mathrm{f}} \_ \text {FE }}{N_{\mathrm{f}} \_ \text {real }}$ & $\begin{array}{l}\text { Max load }(\mathrm{kN}) \\
\text { Load }\end{array}$ & $\begin{array}{c}N_{\mathrm{f}} \text { FE prediction } \\
\text { Life }\end{array}$ & $\begin{array}{c}N_{\text {f }} \text { real laser } \\
\text { Life }\end{array}$ & $\frac{N_{\mathrm{f}} \_\mathrm{FE}}{N_{\mathrm{f}} \_ \text {real }}$ \\
\hline 28 & 29,000 & 60,000 & 2.06897 & 28 & 32,000 & 64,200 & 2.00625 \\
\hline 26 & 57,000 & 165,000 & 2.89474 & 26 & 75,000 & 76,000 & 1.01333 \\
\hline 24 & 108,000 & 205,000 & 1.89815 & 24 & 203,000 & 540,000 & 2.6601 \\
\hline 22 & 215,000 & 302,000 & 1.40465 & 22 & 725,000 & $2,002,000$ & 2.76138 \\
\hline 20 & 450,000 & 300,000 & 0.66667 & 20 & $3,570,000$ & $5,020,000$ & 1.40616 \\
\hline
\end{tabular}

$\frac{\Delta \varepsilon}{2}=\frac{\sigma_{\mathrm{f}}^{\prime}}{E}\left(2 N_{\mathrm{f}}\right)^{b}+\varepsilon_{\mathrm{f}}^{\prime}\left(2 N_{\mathrm{f}}\right)^{c}$

Fatigue tests of the Beam component were conducted at the fatigue stress ratio of $R=0.1$. Fatigue load cycles which have a positive mean stress cause more fatigue damage than a cycle which has zero or negative compressive mean stress. The importance is therefore to find a specific method to accurately predict the lives of laser cut-edges (Table 4).

Comparisons of the FE-based life predictions with those of the physically loaded Beam components with smooth cutedges are shown in Fig. 19. This suggests that the CoffinManson method predictions, with no mean stress correction, gave the closest correlation with the real structure. For the comparatively less damaged laser cut-edges the no mean stress prediction method is the most accurate.

\section{Conclusions}

The fatigue response of cut edges is highly dependent on the steel grade due to the mechanical, microstructural and chemistry properties. It is due to these factors that significantly different cut-edge effects were observed in S355MC and DP600 laser cut edges. A relationship was identified between the width of the laser HAZ and the hardness of the cut edge. It is the thickness of the HAZ that is controlled by the laser process parameters which can be manipulated with adjusting the ratio between power and traverse cutting speed. Surface roughness properties provided an indication of the fatigue life of cut edges. The laser cutting process parameters used during this study have been determined to produce optimum fatigue performance comparable to that of smooth edges.

Laser cut-edges produced when using a power of $2000 \mathrm{~W}$ and a traverse cutting speed of $1.5 \mathrm{~m} / \mathrm{min}$ process parameters displayed the optimum fatigue performance for both DP600 and S355MC. These process parameters resulted in the generation of a flat surface, which less stress rising features. This resulted in a distribution of stress across a large all of the surface. It can, therefore, be recommended that the striation shape significantly influences the fatigue performance of laser cut-edges.

Provided that appropriate process parameters are used to generate laser cut edges, improvements in fatigue life can be gained due to compressive residual stresses produced in the near edge region. This way the traverse cutting speed parameter can be adjusted to alter critical surface characteristics and microstructural properties in close proximity to the cut-edge. The improvements made throughout this work have resulted in a significant increase in the accuracy level for making for fatigue life predictions of cracks initiating from laser cut-edges. 
Acknowledgments The present research was funded by a grant from the Engineering and Physical Sciences Research Council (EPSRC). The author wishes to thank the support of Swansea University Heavy Structures Laboratory during the pursuit of this research.

\section{References}

1. S. Mullick, A.K. Agrawal, A.K. Nath, Effect of laser incidence angle on cut quality of $4 \mathrm{~mm}$ thick stainless steel sheet using fiber laser. Opt. Laser Technol. 81(1), 168-179 (2016)

2. C. Wandera, A. Salminen, V. Kujanpaa, Inert gas cutting of thick-section stainless steel and medium-section aluminum using a high power fiber laser. J. Laser Appl. 21(3), 154-161 (2009)

3. R. Poprawe, W. Schulz, R. Schmitt, Hydrodynamics of material removal by melt expulsion: perspectives of laser cutting and drilling. Phys. Procedia 5(1), 1-18 (2010)

4. C. Wandera, V. Kujanpaa, Characterization of the melt removal rate in laser cutting of thick-section stainless steel. J. Laser Appl. 22(2), 62-70 (2010)

5. L.D. Scintilla, L. Tricarico, A. Mahrle, A. Wetzig, E. Beyer, Experimental investigation on the cut front geometry in the inert gas laser fusion cutting with disk and co 2 lasers. 30th International Congress on Applications of Lasers and Electro-Optics. ICALEO 2011 2011, 40-49 (2011)

6. D.J. Thomas, The influence of the laser and plasma traverse cutting speed process parameter on the cut-edge characteristics and durability of Yellow Goods vehicle applications. J. Manuf. Process. 13(2), 120-132 (2011)

7. S. Cicero, T. García, J.A. Álvarez, A. Martín-Meizoso, J. Aldazabal, A. Bannister, A. Klimpel, Definition and validation of Eurocode 3 FAT classes for structural steels containing oxy-fuel, plasma and laser cut holes. Int. J. Fatigue 87, 50-58 (2016)

8. J. Powell, D. Petring, R.V. Kumar, S.O. Al-Mashikhi, A.F.H. Kaplan, K.T. Voisey, Laser-oxygen cutting of mild steel: the thermodynamics of the oxidation reaction. J. Phys. D 42(1), 015504 (2009)

9. B.S. Yilbas, A.F.M. Arif, Laser cutting of steel and thermal stress development. Opt. Laser Technol. 43(4), 830-837 (2011)

10. A. Lamikiz, L.N.L.D. Lacalle, J.A. Sánchez, D.D. Pozo, J.M. Etayo, J.M. López, $\mathrm{CO}_{2}$ laser cutting of advanced high strength steels (AHSS). Appl. Surf. Sci. 242(3-4), 362-368 (2005)
11. B.T. Rao, R. Kaul, P. Tiwari, A.K. Nath, Inert gas cutting of titanium sheet with pulsed mode $\mathrm{CO}_{2}$ laser. Opt. Lasers Eng. 43(12), 1330-1348 (2005)

12. J. Powell, S.O. Al-Mashikhi, A.F.H. Kaplan, K.T. Voisey, Fibre laser cutting of thin section mild steel: an explanation of the 'striation free' effect. Opt. Lasers Eng. 49(8), 1069-1075 (2011)

13. A. Lara, I. Picas, D. Casellas, Effect of the cutting process on the fatigue behaviour of press hardened and high strength dual phase steels. J. Mater. Process. Technol. 213(11), 1908-1919 (2013)

14. E. Nagels, J.R. Duflou, J. Van Humbeeck, The influence of sulphur content on the quality of laser cutting of steel. J. Mater. Process. Technol. 194(1-3), 159-162 (2007)

15. B.S. Yilbas, C. Karatas, I. Uslan, O. Keles, Y. Usta, Z. Yilbas, M. Ahsan, Wedge cutting of mild steel by $\mathrm{CO}_{2}$ laser and cut-quality assessment in relation to normal cutting. Opt. Lasers Eng. 46(10), 777-784 (2008)

16. L.D. Scintilla, L. Tricarico, Estimating cutting front temperature difference in disk and $\mathrm{CO} 2$ laser beam fusion cutting. Opt. Laser Technol. 44(5), 1468-1479 (2012)

17. H.A. Eltawahni, M. Hagino, K.Y. Benyounis, T. Inoue, A.G. Olabi, Effect of $\mathrm{CO}_{2}$ laser cutting process parameters on edge quality and operating cost of AISI316L. Opt. Laser Technol. 44(4), 1068-1082 (2012)

18. M. Lin Li, P.L. Sobih, Crouse striation-free laser cutting of mild steel sheets. CIRP Ann. Manuf. Technol. 56(1), 193-196 (2007)

19. K. Kheloufi, A. El Hachemi, Numerical investigation of the effect of some parameters on temperature field and kerf width in laser cutting process. Phys. Procedia 39, 872-880 (2012)

20. A. Lamikiz, L.N. López de Lacalle, J.A. Sánchez, D. del Pozo, J.M. Etayo, J.M. López, $\mathrm{CO}_{2}$ laser cutting of advanced high strength steels (AHSS). Appl. Surf. Sci. 242(3-4), 362-368 (2005)

21. D.J. Thomas, M.T. Whittaker, G.W. Bright, Y. Gao, The influence of mechanical and $\mathrm{CO}_{2}$ laser cut-edge characteristics on the fatigue life performance of high strength automotive steels. J. Mater. Process. Technol. 211, 263-274 (2011)

22. D.J. Thomas, The influence of the laser and plasma traverse cutting speed process parameter on the cut-edge characteristics and durability of Yellow Goods vehicle applications. J. Manuf. Process. 13, 120-132 (2011) 